Original Research

\title{
The Factors Related to the Caring Behavior of Clinical Nursing Students
}

\section{Tintin Sukartini, Candra Panji Asmoro and Fiqih Ardi Pradana}

\author{
Faculty of Nursing, Universitas Airlangga, East Java, Indonesia
}

\begin{abstract}
Introduction: The CB of clinical nursing students is very important but they are still in the implementation phase of the theory from when it was learned in college. This study aims to describe the correlation between intelligence quotient (IQ), emotional intelligence (EI) and spiritual intelligence (SI) with caring behavior (CB).

Methods: This study was descriptive and correlational with a cross-sectional approach. The respondents of this research were all of the clinical nursing students (166 respondents) via the simple random sampling technique. The data was collected using questionnaires and analyzed using the Spearman-rho test with a level of significance $\leq 0.05$.
\end{abstract}

Results: The results showed that CB had a correlation with IQ ( $p=0.019, r=0.211)$, EI ( $p=0.048, r=0.178)$ and SI $(p=0.000, r=0.456)$.

Conclusion: IQ, EI, and SI have a correlation with CB. A higher quotient will produce a higher $\mathrm{CB}$. Future research is expected to be able to analyze the other factors related to $\mathrm{CB}$ among clinical nursing students.

\section{ARTICLE HISTORY}

Received: Feb 27, 2019

Accepted: Nov 22, 2019

\section{KEYWORDS}

intelligence quotient; emotional intelligence; spiritual intelligence; $\mathrm{CB}$; clinical nursing student

\section{CONTACT}

\begin{tabular}{l} 
Candra Panji Asmoro \\
$\square$ \\
candra.panji.a@fkp.unair.ac.id \\
\hline$\Xi$ Faculty of Nursing, \\
Universitas Airlangga, East \\
Java, Indonesia
\end{tabular}

Cite this as: Sukartini, T., Asmoro, C.P., \& Pradana, F.A. (2019). The Factors Related to the Caring Behavior of Clinical Nursing Students. Jurnal Ners, 14(1), 82-86. doi:http://dx.doi.org/10.20473/jn.v14i1.12154

\section{INTRODUCTION}

Clinical nursing students are fully implemented in practical health settings such as hospitals, health centers, maternity hospitals, nursing homes, families, communities and societies (Nursalam, 2015). The practice of student clinics has so far been deemed to lack the caring attitude of prospective professional nurses. Unlike the nurses who already have the full authority to treat patients, students are often required to behave in the same caring manner as professional nurses. Therefore, studies are needed to explain what factors influence the CB of students in their clinical practice in hospitals.

Caring is a special form of performance made by the nurses and the clinical nursing students who are enrolled on the nursing profession program of education. Swanson (Swanson, 1991) stated that Caring is a nursing technique in relation to the value of one's feelings about commitment and responsibility. In the theory of the Middle Range Theory of Caring, Swanson (Swanson, 1991) found that the five processes of Caring involve becoming more practical. They are maintaining belief, knowing, being with, doing for (active component) and enabling (possible component).
Gibson (Gibson, J. L., Ivancevich, J. M., \& Donnely, 1987) stated that a person's behavior and performance is influenced by three factors. These factors are individual factors, psychological factors and organizational factors. Gibson et al (Gibson, J. L, Ivancevich, J. M, Donnelly, J. H., \& Konopaske, 2012) found that the variables of ability and skill under the individual factors are the main factors that influence a person's behavior and performance. According to Hawari, the skill of intelligence is divided into four kinds of intelligence. These kinds are IQ, EI, SI, and creative quotient (Hawari, 2006).

IQ is the cognitive ability that is interpreted as IQ where the ability includes achievement in learning and problem solving (Behling, 1998). IQ refers to being smart, intelligent and clear-minded based on the knowledge that can be described as including academic and non- academic learning achievements (Ministry of Education and Culture, 2000). The knowledge of nursing can be seen in the behavior of caring (Swanson, 1993). Nursing students are potential nurses in the future that will have academic qualifications. They will also have the right to $\mathrm{CB}$ (Murphy, F. \& Robert, 2009). Rhodes identified that the intellectual level of a student will challenge his 


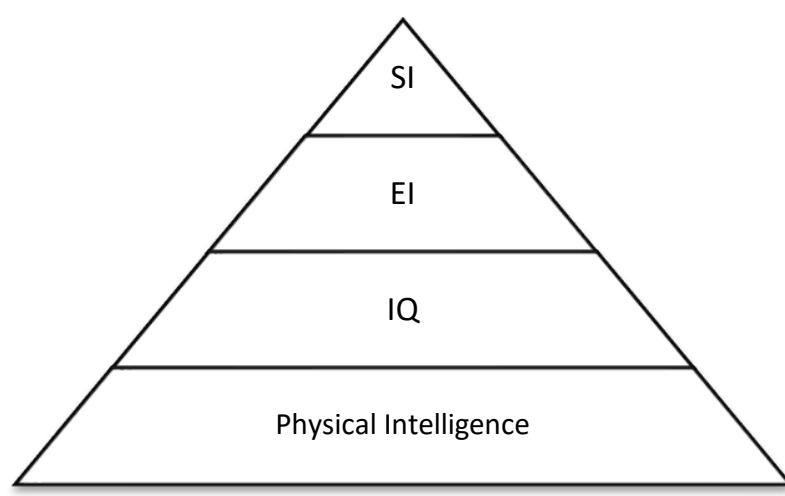

Figure 1 - Significance of SI and EI on the CB of Nurses: A Simple Model of Four Intelligences by Gardner 1983 (Kaur \& Sambasivan, 2015).

intellect as a part of gaining their nursing knowledge and skills (Rhodes, M. K., Lazenby, R., \& Moris, 2011).

EI is the ability to motivate yourself and to survive when facing problems. It is about relying on the spirit and not being too excessive in terms of pleasure. It is also about managing one's moods, avoiding stress, the ability to think, to empathize and to pray (Goleman, 2015). The elements of EI were self-awareness, selfmanagement, motivation, empathy and social skills.

SI is a set of mental capacities that including taking responsibility for awareness, integration, and the non-material aspects of adoption used. It is the things that are realized in the transcendent area (King, 2008). There are four aspects that can be observed in SI, each of which represents the measurements within the SI Self-Report Inventory Questionnaire (SISRI-24). They were Critical Existential Thinking (CET), Personal Meaning Production (PMP), Transcendental Awareness (TA) and Conscious State Expansion (CSE). The purpose of this study is to describe the correlation between IQ, EI, and SI with CB.

\section{MATERIALS AND METHODS}

This study was descriptive and correlational with a cross-sectional approach. The study was conducted in the Faculty of Nursing (FoN) Universitas Airlangga (UA) between October and December 2018. The independent variables in this study were IQ, EI and SI. The dependent variable of this study was CB. The population of this study consisted of the clinical nursing students of the FoN UA 2018. The total sample in this study was 123 people chosen using simple random sampling. The procedure of the data collection in this study was divided into two stages, namely preparation and implementation. The preparation stage involved licensing and two tests, namely ethical testing and the validity and reliability test focused on the questionnaire. The first step was where the researcher tested the validity and reliability of the questionnaire. The researcher adopted the questions on each variable from the previous research conducted in Indonesia (within a span of five years). The ethical test phase was carried out at the Ethics Committee of the FoN UA. The results of the ethical test were that the study had an ethical score of 1187-KEPK. The researcher received a research permit from the FoN UA.

The next stage was implementation. This stage was the step used for collecting the research data from the respondents. The researcher obtained a list of clinical nursing students from FoN UA. This was used by the researchers to conduct sampling according to the criteria previously set. The questionnaires were distributed to the respondents and they filled out the informed consent sheet after the researcher explained the purpose and benefits of the research. Next, the researcher calculated the score from each questionnaire by summing up each answer to the questions. The final results were obtained by the total score used to analyze the data. This was done using the Spearman Rho test with a p value $<0.05$.

The academic workload questionnaire was adapted from Wijaya (Wijaya, A., 2015). IQ was taken from the academic score data. The EI questionnaire adopted was a questionnaire by Iswanto (2014) (Rifai, 2017). The SI questionnaire was adopted from Wulandari (2013). The CB questionnaire was taken from the caring, professional scale (CPS), which is the standard questionnaire. All of the questions were tested for validity and reliability.

\section{RESULTS}

Table 1 shows that most of the respondents were women. For the age of the respondents, nearly half of them were aged 22 years old. The majority of the respondents were Force A14. Most of the respondents - almost half - exist in the category of stage management.

Table 2 indicates that the IQ of the respondents can be viewed from their academic score. Most of the academic scores were in the range of 2.76 to 3.50 with honors. The EI clinical nursing students in 2018 at the FoN UA, Universitas Airlangga, were found mostly to be in the medium category. The SI clinical nursing students in 2018 at the FoN UA were mostly found to be in the medium category. The clinical nursing students and CB nurses in 2018 from FoN UA were found to be mostly in the high category.

Table 3 shows that IQ has a correlation with CB although the strength of the correlation is weak. EI has a correlation with $\mathrm{CB}$ and the strength of the correlation is very weak. SI has a correlation with $\mathrm{CB}$ with a medium correlation strength.

\section{DISCUSSION}

\section{The correlation between IQ and CB}

IQ has a weak correlation with the caring behavior done by the students. This means that the higher IQ that the students have, the higher the caring behavior of the clinical nursing students.

This is in line with the research conducted by Wijaya (Wijaya, A., 2015). The results of his study stated that IQ (GPA) has a relationship with a moderate correlation. The number of respondents 
Table 1. Characteristics of the Respondents $(n=123)$

\begin{tabular}{lcc}
\hline Characteristics & f & \% \\
\hline Gender & & \\
Man & 25 & 20.3 \\
Woman & 98 & 79.7 \\
Age & & \\
21 & 17 & 13.8 \\
22 & 52 & 42.3 \\
23 & 31 & 25.2 \\
24 & 17 & 13.8 \\
25 & 6 & 4.9 \\
Class & & \\
B19 & 54 & 43.9 \\
A14 & 69 & 56.1 \\
Stage & & \\
Management & 36 & 29.3 \\
Emergency & 17 & 13.8 \\
Geriatric & 5 & 4.1 \\
Child & 17 & 13.8 \\
Soul & 4 & 3.3 \\
Community & 17 & 13.8 \\
Maternity & 20 & 16.3 \\
Medical-surgical & 7 & 5.7 \\
\hline
\end{tabular}

totaled 26 respondents with the level of caring in the medium range. The category of IQ of the respondents was found to be very satisfying/moderate. It was also stated by Murphy (Murphy, F. \& Robert, 2009),that the higher the educational qualifications or academic achievements of the students, the better the quality of caring by the nurses. The higher the intelligence of the individual, the lower the level of human error related to the caring done by the nurses. This could increase the quality of the behavior related to the caring of an individual.

According to Gibson (Gibson, J. L., Ivancevich, J. M., \& Donnely, 1987), the factors that influence performance are the abilities and skills where intelligence is one of the main factors associated with individual behavior and performance. Swanson (Swanson, 1991) found out that the first domain associated with CB refers to a person's capacity to pay attention. IQ or intelligence (IQ) can be defined as the ability to work in a theoretical way using ideas, symbols, logical relationships and theoretical concepts. This is the ability to recognize, learn and use these preliminary concepts. The ability to solve problems belongs to a new issue (Hawari, 2006). Rhodes stated that the intellectual level of a student relates to the challenge to his intellect in order for them to gain the knowledge, abilities and skills involved in nursing (Rhodes, M. K., Lazenby, R., \& Moris, 2011).

A high intellectual ability will make it easier for the students to remember and use their knowledge in performance, which is called CB. Increasing the level of $\mathrm{CB}$ done by the clinical nursing students belongs to knowledge, as does studying with the lecturers and benefiting from their guidance while in the practical settings. The more IQ that the individual has, the students will be able to understand and apply the theory more. A high IQ score means that the students are expected to have a good memory. While the students use their theory knowledge, they can minimize the human error factor of performance and caring. It is expected that the students can improve their performance and caring in order to be better.

\section{The correlation between EI and CB}

EI has a correlation with $\mathrm{CB}$, although it is a very weak correlation. This has the meaning that the higher the EI, the higher the CB that the students have.

In the research conducted by Rifai (Rifai, 2017), it was found that there was a significant relationship between EI and the caring behavior of the nurses. While implementing the factors of recognizing selfemotion, controlling self-emotion, motivating oneself, and establishing relationships and empathy in the process of nursing, it will lead to a good CB in the patients. According to Kaur and Sambasivan (Kaur, D. \& Sambasivan, 2015), they stated that EI has a highly significant relationship with the $\mathrm{CB}$ of the nurse. EI is not obtained instantly. It is obtained through the mechanisms of training, education and other things that enhance the comprehension of their nursing knowledge. In addition, according to Nightingale et al. (Nightingale, S., Hsiang, C.P., \& Eng, 2018) in his research, it was found that the more that the nurses develop their EI, the more they can increase the CB of the nurses spontaneously. The more that the EI of the nurses' increases, the more that the nurses will be professional when doing CB, including being smart when solving problems and increasingly being able to lead when it comes to solving nursing problems.

Goleman (Goleman, 2015) stated that EI is the ability to motivate oneself and how to survive when facing problems, including relying on spirit and not being too excessive in terms of pleasure, to manage their moods, to avoid stress and the inability to think, to empathize and to pray. The aspect of EI is closely related to CB in nurses. It can be seen that aspects of EI become an important component in influencing the nurses' behavior. Swanson (Swanson, 1993) stated that CB is closely related to empathy. The nurses who are able to do caring well will show empathy to their patients. The nature of empathy is the main element of EI. Besides that, holding in anger in the area of nursing is also closely related to optimal caring.

$\mathrm{EI}$ is a non-academic intelligence that must be learnt by the students in order for them to be able to do caring properly. For the factor of self-awareness, the clinical nursing students must be careful when carrying out nursing care. They must be able to adapt to the practice environment and they must be able to innovate if there is a gap between theory and practice. We have then focused on the self-regulation factors that influences caring. Clinical nursing students are required to be able to withstand emotions if there are undesirable things encountered in the professional practice environment. This is because it will greatly interfere with the process of the client's recovery and the performance of the nursing care services.

Empathy is the closest factors of EI to CB. The level of empathy held by each individual is different. At the lowest level, empathy requires the ability to feel other's emotions. At the highest level, empathy 
Table 2. IQ, EI, SI and CB Clinical Nursing Students $(\mathrm{n}=123)$

\begin{tabular}{lcc}
\hline Variables & f & \% \\
\hline IQ (GPA score) & & \\
2.00 to 2.75 (Excellent) & 1 & 0.8 \\
2.76 to 3.50 (Honors) & 83 & 67.5 \\
$\quad$ 3.50 to 4.00 (Cum laude) & 39 & 31.7 \\
EI & & \\
Low & 1 & 0.8 \\
$\quad$ Medium & 79 & 64.2 \\
High & 43 & 35.0 \\
SI & & \\
Low & 2 & 1.6 \\
Medium & 86 & 69.9 \\
High & 35 & 28.5 \\
CB & & \\
Low & 4 & 3.3 \\
Medium & 51 & 41.5 \\
High & 68 & 55.3 \\
\hline
\end{tabular}

Table 3. Workload, Academic Relations, IQ, EI and SI of the CB Clinical Nursing Students $(n=123)$

\begin{tabular}{lll}
\hline \multirow{2}{*}{ Independent } & \multicolumn{2}{c}{ Dependent } \\
\hline IQ & $p$ value: 0,019 & $r: 0211$ \\
EI & $p$ value: 0,048 & $r: 0.178$ \\
SI & $p$ value: 0,001 & $r: 0.456$ \\
\hline
\end{tabular}

requires someone to feel while responding to someone else's needs or feelings that are not described in words. Then there are the factors related to the social skills that influence $\mathrm{CB}$. The main meaning of social skills is the art of dealing with the other's emotions. This is the basics of several skills such as the medical devices used in doing $\mathrm{CB}$, being able to communicate therapeutically with patients and their colleagues and being able to manage any problems faced so then it does not appear again during the process of caring. The last factor is the motivation that influences CB. Managing emotions such as paying attention, motivating and knowing oneself, and being creative are all very important things in order to achieve the goals before them.

\section{The correlation between SI and CB}

SI has a correlation with the CB of clinical nursing students with a moderate correlation. This means that the higher the SI that the students have, the better that the clinical nursing students behave in terms of caring.

These results are in line with the study of Hossein (Hossein, 2015) which stated that SI with CB and clinical competence results in a good quality of caring. This is in line with the increasing number of nurses with good clinical competence who will also deal with CB and SI. It was also stated by Moradnezhad that increasing SI will improve the spiritual care provided, in addition to $\mathrm{CB}$ and the quality of care given by the university students. The nurses' spirituality can also reduce their stress level in their job (Moradnezhad, 2017).

According to King (King, 2008), SI is defined as a set of mental capacities that contribute to the awareness, integration, and application of adaptive non-material aspects to consider in the area of the transcendent, leading to results such as deep existential meaning improvement, the recognition of self-transcendence, and mastery of the spiritual arena. This is supported by the theory of SI put forward by Zohar \& Marshall (Zohar, D. \& Marshall, 2010). SI is the intelligence that is created to deal with and solve some of the problems present in meaning and value. Subjects sometimes get confused because there is still a difference between religious and spiritual concepts. The subjects must have a good spiritual level to be able to perform their service tasks optimally. Nursing and CB services are very important when looking to get positive results on the health and well-being of clients (Swanson, 1991). Caring is not merely just doing the action so then it is finished. It must also present a caring nature that works together with the nurse's spirituality focused towards the client.

SI is the highest intelligence that can be possessed by humans. SI can control individual behavior to encourage them to take action according to the right thing to do. Therefore, the nurses' and clinical nursing students' spirituality should be established in order to achieve good CB. For the existential critical thinking factors that influence $\mathrm{CB}$, clinical nursing students must be able to understand the reality that they are facing which is dealing with individuals who need help, treatment rooms that have many patients, time to reflect on or think and then interventions to carry out limited nursing care and death. The more capable their existential critical thinking, the more it is hoped that this will increase the $\mathrm{CB}$ that is possessed. In forming the self-perception of factors that affect caring, the components included are the elements of the adaptability of the meaning and purpose of life and the reason to live, the meaning of failure, making decisions in accordance with the purpose of life, and the meaning and purpose of daily events. From the components above, it is expected that the respondent can learn the meaning in order to be able to do CB properly.

In the transcendental intelligence factor or the ability to perceive the spiritual dimension of life, it is about reflecting what was previously described as feeling a more tangible, wider spread presence and our special senses. The last factor is the development of the area of consciousness. Self-awareness is the main differentiator between people who have a high level of spirituality and those who do not. People who have high awareness will always think several times before responding to each situation, and taking a moment to understand what is hidden or real before doing the initial response. They always act in a manner that is calculated, considered and cautious. Moreover, the clinical nursing students, are required to think more deeply when facing each situation so then they are not mistaken when carrying out nursing. 


\section{CONCLUSION}

IQ has a correlation with CB. The high score of IQ can be seen from the high GPA that makes for good CB. EI has a correlation with CB. A higher EI will make for good CB. SI has a correlation with CB. A higher SI will make for good CB.

The clinical nursing students are expected to maintain their CB. For students who have CB at a moderate level, they are expected to improve their quality of CB by increasing their self-regulation, motivation, social skills, critical thinking, the shaping of their personal perception, transcendental awareness and the development of other areas of awareness in order to become clinical nursing students after finishing their education. For institutions, it is necessary to provide people who have competence in religion to teach nursing and to provide emotional training for the clinical nursing students. For further research, this study could be developed further in order to be able to analyze the other factors related to the $\mathrm{CB}$ of clinical nursing students.

\section{REFERENCES}

Behling, O. (1998). Employee Selection: Will Intelligence and Conscientiousness Do The Job.

Gibson, J. L, Ivancevich, J. M, Donnelly, J. H., \& Konopaske, R. (2012). Organization: Behavior, Structure, Processes (14th ed.). New York: McGraw-Hill.

Gibson, J. L., Ivancevich, J. M., \& Donnely, J. H. (1987). Organisasi: Perilaku, Struktur, Proses (1st editio). Jakarta: Binarupa Aksara.

Goleman, D. (2015). HBR's 10 Must Reads on EI. Jakarta: Gramedia Pustaka Utama.

Hawari, D. (2006). IQ, EQ, CQ dan SQ: Kriteria SDM (pemimpin) Berkualitas. Jakarta: FKUI.

Hossein, K. M. (2015). Relation between spiritual intelligence and clinical competency of nurses in Iran. Iranian Journal of Nursing and Midwifery Research, 20(6), 665. https://doi.org/10.4103/1735-9066.170002
Kaur, D. \& Sambasivan, M. (2015). Significance of spiritual (SI) and emotional intelligence (EI) on the caring behavior of nurses. Journal of Community and Public Health Nursing, 1(2), 2-4. https://doi.org/10.4172/2471-9846.1000101

King, D. B. (2008). Rethinking Claims of Spiritual Intelligence: A Definition, Model, and Measure. Trent University.

Moradnezhad, M. (2017). Nursing practice today. Journal of Medical Ethics and History of Medicine, 4(4), 170-179.

Murphy, F. \& Robert, S. (2009). The impact of nurse education on the caring behaviours of nursing students. Nurse Education Today, 29(2), 254-264. doi: 10.1016/j.nedt.2008.08.016.

Nightingale, S., Hsiang, C.P., \& Eng, C. J. (2018). The impact of emotional intelligence in health care professionals on caring behaviour towards patients in clinical and long-term care settings: Findings from an integrative review. International Journal of Nursing Studies, 80, 106-117. doi: 10.1016/j.ijnurstu.2018.01.006.

Nursalam. (2015). Manajemen Keperawatan: Aplikasi dalam Praktik Keperawatan Profesional (Edisi 5). Jakarta: Salemba Medika.

Rhodes, M. K., Lazenby, R., \& Moris, A. H. (2011). Nursing at its best: competent and caring. The Online Journal of Issues In Nursing, 16(2).

Rifai, F. (2017). Hubungan Kecerdasan Emosional dengan Perilaku Caring pada Perawat di Ruang Marwah RS Haji Surabaya. Universitas Airlangga.

Swanson, K. M. (1991). Empirical development of a middle range theory of caring'. Journal of Nursing Scholarship, 40(3).

Swanson, K. M. (1993). N as informed caring for the well-being of others. Journal of Nursing Scholarship, 25(4), 352-357. doi: 10.1111/j.15475069.1993.tb00271.x

Wijaya, A., et al. (2015). Indonesian nursing students in caring behavior. Journal of Nursing and Health Care, 2(2), 1-4. https://doi.org/10.5176/20104804_2.2.75

Zohar, D. \& Marshall, I. (2010). SI: Kecerdasan Spiritual (Edisi 7). Bandung: Mizan Media Utama. 